\title{
Differences between Students and Professionals While Using a GPS Based GIS in an Emergency Response Study
}

\author{
Rego Granlund ${ }^{1}$, Helena Granlund ${ }^{1,2}$, and Nils Dahlbäck ${ }^{3}$ \\ ${ }^{1}$ Santa Anna IT Research Institute, Linköping, Sweden \\ ${ }^{2}$ Swedish Defence Research Agency, Linköping, Sweden \\ ${ }^{3}$ Linköpings Universitet, Linköping, Sweden \\ rego.granlund@santaanna.se, helena.granlund@santaanna.se, \\ nilda@ida.liu.se
}

\begin{abstract}
This paper describes the results and differences between students and professionals who used a GPS based GIS as a collaborative tool in an experimental emergency response study. A total of 132 students, forming 22 groups and 108 professionals forming 18 groups were tested. Differences in both performance and behaviors between the groups have been identified. In the discussion we reflect on the importance to be aware of the participants' background and behaviors while selecting the participants in an experimental study.
\end{abstract}

Keywords: Experiment, Collaboration Support, Global Position Systems, Simulation, Emergency Management.

\section{Introduction}

This paper compares the results from a research project that includes two experiment studies. The experiment series was conducted with the same experimental method, but with different participant groups. In the first series, was the research idea tested on non-professional participants, a total of 132 university students. In the second series, 18 Swedish municipal crisis management teams, a total of 108 professionals were tested. The project explored the differences in work processes between teams that had access to GPS information in their digital map systems at command post level, compared to teams that only had paper maps (Johansson et al, 2010, Granlund et al, 2010, Granlund et al, 2011).

In Sweden many municipal organizations have made, or is about to make, investments in information and communications technologies, which provides crisis managers and rescue service personnel access to GPS information in all levels of command. The investments are done in order to enhance performance and control in response work.

GPS and digital maps are seen as support tools for crisis management that is understood to be more efficient with the introduction of these new technical supports. The reality is that they are tools that can distribute large amounts of information automatically to all users at all levels of management simultaneously. What originally 
was seen as an aid in the management work may have unforeseen consequences. The tools may change the requirements for managing and organizing emergency efforts.

\subsection{Students vs Professionals}

In many experimental studies, as is the case in much research, students are used as participants. There are of course some good reasons for this practice; one obvious one is the availability of large groups of participants, while using professional participants requires a laborious and time consuming process to recruit a large enough set of participants. And in addition, if working with rescue service professionals, there is always the risk that a real emergency occurs, forcing the data collection to be cancelled.

But using students as participants are not without problems, and this has been known for a long time. For an early example, see e.g. Smart's classical paper Subject Selection Bias in Psychological Research (Smart, 1966). Among the factors that Smart and his followers have pointed out where students differ from the general population are age, educational level, social background, where these in turn are known to co-wary with many variables potentially influencing performance in the tasks under study, e.g. intelligence, social skills etc.

Another factor which more recently has been brought to attention is that almost without exception student volunteers are exactly that, i.e. volunteers. If volunteering co-varies with factors potentially influencing the task under study, this limits the generalizability of the results obtained. Dahlbäck and Karsvall (2000) found for instance that the vast majority of participants were extrovert personalities, a factor which in turn is known to co-vary with communication patterns and risk-taking to mention a few.

All this calls for caution when using student volunteers as participants. But one can also note that all of the work mentioned above, as well as research reviewed in these papers, concern rather artificial lab experiments. It becomes therefore of interest to study whether student volunteers' performance differs from professionals in more ecologically valid settings, like for instance in microworld experiments. In this paper we will therefore compare both performance and communication patterns of students and professionals in exactly the same experimental situation.

\section{Method}

The method used for the two studies was controlled experiments in the microworld simulation C3Fire (Granlund, 2001; Johansson et al., 2007; Granlund et al., 2010). During the experiment series the participants experienced a set of scenarios, where an emergency response task was simulated. Half of the participating teams performed the task with a GPS support. Half of the participating teams were supported with paper maps.

\subsection{C3Fire}

The C3Fire microworld is a simulated environment where the system designers select important characteristics of the real system and create a small and well-controlled 
simulated system based on these characteristics. C3Fire often generates a dynamic forest fire fighting task and has been used extensively in previous research on network-based command and control (www.c3fire.org, Artman and Wearn, 1999; Granlund, 2001, 2004; Johansson et al., 2004), on effects concerning information support systems (Johansson et al., 2010; Granlund et al., 2010), on cultural differences in teamwork (Lindgren \& Smith, 2006a, 2006b), and comes from a long tradition of microworld research on distributed decision making (Brehmer, 2005; Brehmer and Dörner, 1993).

The advantage of using a microworld is that the complex, dynamic and opaque characteristics that are generated by a proper microworld represents the cognitive tasks people encounter in real-life systems. Microworlds allows for the presentation of a number of different problems for the participants, rather than a single, welldefined task (Brehmer and Dörner, 1993; Dörner \& Schaub, 1994; Granlund, 2001).

In this study the C3Fire system generates a task environment where participants can take on different roles, as commanders in a command post or fire fighting ground chiefs. The command post and the ground chiefs need to co operate to put out one or more forest fires. The simulation includes forest fire, houses, different kinds of vegetation, wind, and fire fighting units. The ground chiefs are responsible for the low level operation, such as the fire fighting, which is done in a short time frame. The command post works at a higher level and is responsible for coordinating the fire fighting forces and strategic thinking (Figure 1 and 2).

Computer based monitoring are integrated in the simulation and in all the information tools, used for the C3Fire environment. During a simulation the C3Fire environment creates a log with all events in the simulation and all computer mediated activities (Granlund, 2001).

\subsection{Two Participant Groups}

The two studies had different participant groups. In Study 1, conducted 2006, the participant group was Swedish university students. 22 student groups with six persons in each group were tested, giving a total of 132 participants (Johansson et al 2007, 2010).

In Study 2, conducted 2008-2009, the participant group was Swedish municipal crisis management members. Their average age was 49 years. 18 groups with six persons in each group were tested, giving a total of 108 crisis management members (Granlund et al, 2010; Granlund et al, 2011).

\subsection{Experiment Design}

Study 1 and Study 2 had the same between-group design with one factor: (a) crisis management teams using GPS, and (b) crisis management teams using paper maps (Figure 1 and 2). The difference between the two conditions is the type of support the participants obtain in terms of information visualization and data sources.

In each six person group, three participants worked as command post with one commanding officer and two liaison officers. Three participants worked as ground chiefs, controlling fire fighting units in the simulated environment. 
In the GPS condition the commanding officer had access to a computer terminal equipped with a GPS that provided access to different digital map layers containing geographical information and exact positioning of the resources in the simulated world. The two liaison officers had computer terminals for communication with the ground chiefs in terms of e-mails (Figure 1).

In the paper map condition the commanding officer had no GPS access, but only a paper map of the simulated area. The two liaison officers had computer terminals for communication with the ground chiefs in terms of e-mails (Figure 2).

The ground chiefs in both conditions had access to a computer terminal with a single layer digital map and a communication tool that made it possible to communicate with the command post (Figure 1 and 2).

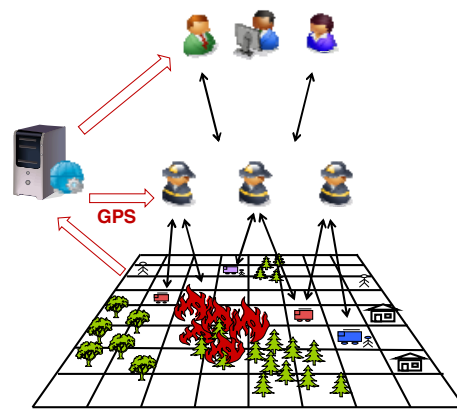

Fig. 1. The GPS condition

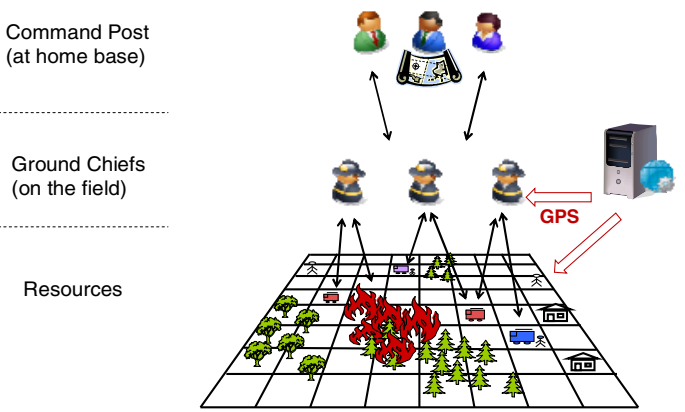

Fig. 2. The Paper Map condition

The resources were nine fire fighting units controlled by the ground chiefs. The task, the resources and the organization created the complexity of the experiment session.

\subsection{Experiment Procedure}

The experiment procedure included a customary training, then five regular simulation cycles. Each cycle include a $20 \mathrm{~min}$ simulation trial, $5 \mathrm{~min}$ of reflective questionnaires and $20 \mathrm{~min}$ of joint reflection, and after action review, where the group sees a fast recording of their actions during the simulation trial (Figure 3) (Granlund, 2008).

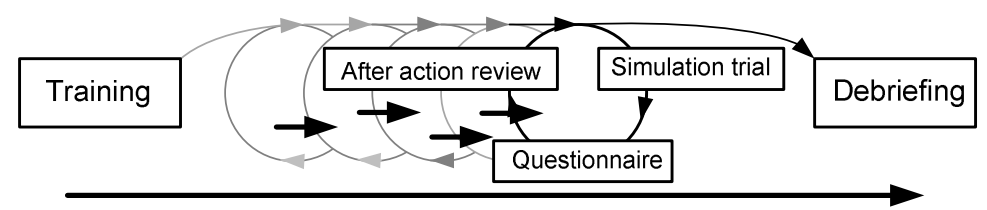

Fig. 3. The experiment procedure 


\section{Results}

The results from the two studies, with students and professionals, are presented with respect to the two conditions GPS and Paper Map and with regards to performance and communication volume.

\subsection{Performance}

The main task for the participating teams was to control the forest fire and save houses. The measure of the success and performance of the team is a measure of the total amount of burned down area at the end of each simulation. A small amount on BurnedOutArea is preferable to a large.

Study 1. For students the results show, an over all significant difference, $P=0,021$ $(\mathrm{N}=132)$, between GPS and Paper Map over the five simulation trials (Johansson et al, 2010). The groups with a GPS support have lesser amount of BurnedOutArea, a better performance, than the groups who used Paper Maps (Figure 4).

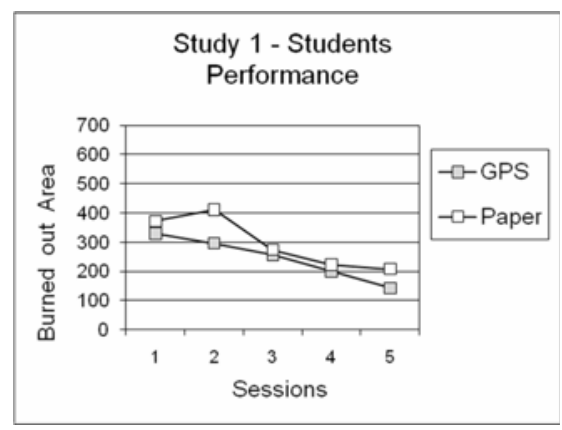

Fig. 4. Performance Student

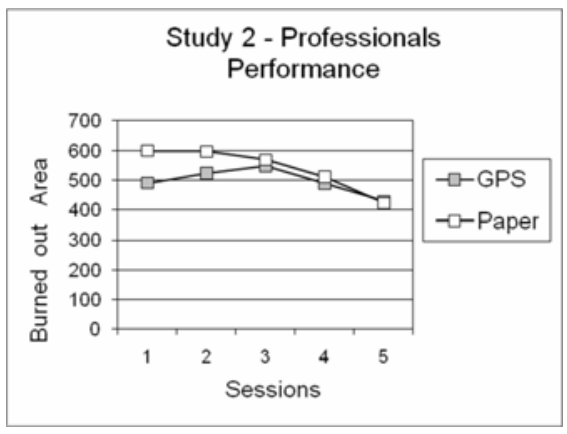

Fig. 5. Performance Professionals

Study 2. For professionals as participants there is no over all performance difference between GPS and Paper Map in the simulation trials and the trend of teams with GPS to have a smaller amount of BurnedOutArea is definitely broken in simulation session 5 (Figure 5). The professionals perform not as good as the students and have clearly inconsistent results compared to study 1 .

One explanation for the results is that the command post of the participating groups is not uniform but has various compositions. The result above is divided into two subgroups. Teams where the command post consists solely of rescue service personnel, and subgroups in which the command post consist of a mix of municipal personnel (crisis management personnel), and rescue service personnel. The rescue service teams consist of a relatively homogeneous set of personnel with joint training and experience, and with a professional experience in managing crisis events. The 
mixed teams consist of a diverse group with a variety of training and professional experience, where one fraction of the participants is used to manage crisis events, while the other is familiar with management under normal conditions.

The result then shows that rescue personnel behave as expected from study 1 (Figure 6 and 7). But mix of municipal personnel and rescue personnel does not follow the patterns from study 1 . The support tool did not help the mixed groups (Granlund et al. 2011).

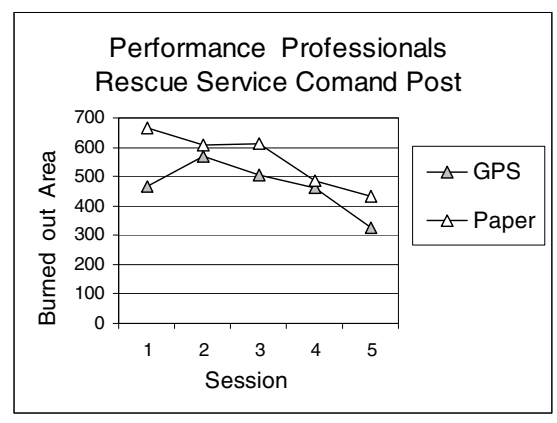

Fig. 6. Performance Rescue Service

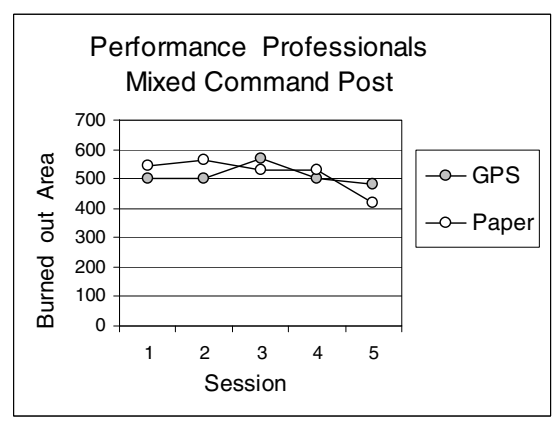

Fig. 7. Performance Mixed Teams

Summary Performance. Students have an over all significant difference in performance, where teams using GPS performs better than teams using Paper Maps. Professionals do not show any significant over all performance result between teams using GPS and teams using Paper Maps. When dividing the professional to sub groups, the rescue personnel behave as expected but not the mixed teams.

\subsection{Communication Volume}

This section present the volume of communication as amount of send messages between command posts and ground chiefs.

Study 1. The results for students show a difference in the patterns of communication between ground chiefs and command post in the GPS condition and the paper map condition in total over the five sessions (Figure 8). In the fifth simulation trial the command post of the GPS and paper map conditions send equally many text messages as the ground chiefs of the paper map condition, on average 80 messages. The ground chiefs of the GPS condition sent lesser than half of the amount, on average 30 text messages. This means that the ground chiefs in the GPS condition are relieved of workload when it comes to amount of sent messages, not the command post. 


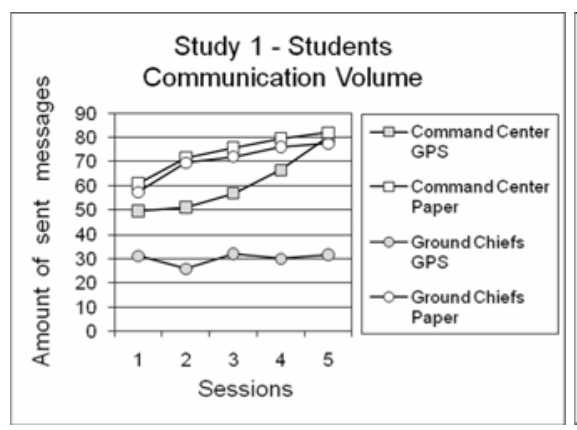

Fig. 8. Communication Students

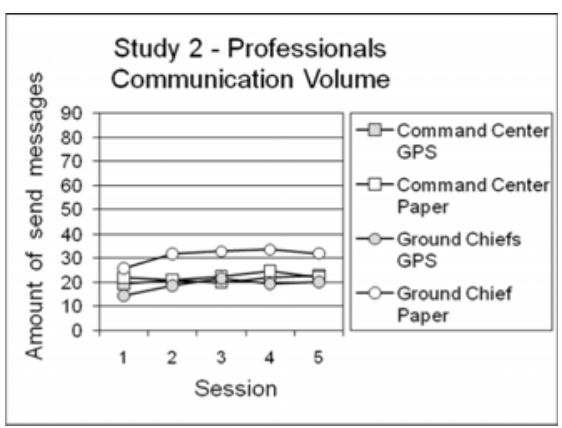

Fig. 9. Communication Professionals

Study 2. The crisis management personnel in study 2 show the same trend in the results for the amount of send messages (Figure 9). In the fifth session as many emails, about 22, are sent from the command post of teams that have access to a GPS support as from those who perform the task by using a paper map. This means that the command post is not relieved from work due to the GPS-based management support, with regards to the volume of communication. The second is that the ground chiefs in the GPS condition sends significant, $\mathrm{t}(16)=3.13, \mathrm{p}<.006$, less messages than ground chiefs of the paper map condition. This means that it is the ground chiefs in the GPS condition that are relived of work load.

Summary Communication. Firstly there is a significant difference in amount of send messages between command posts in study 1 and study $2, \mathrm{t}(78)=4.25, \mathrm{p}<0.0001$. The command posts in study 1 sent on an average 80 messages. The command posts in study 2 sent about 22 . That is a significant difference. The ground chiefs in study 1 follow the same trend of sending more messages than ground chiefs in study 2 .

By analyzing the amount of send messages from each entity, command post or ground chiefs, a picture of the teams' workload emerge. Study 1 and 2 shows two trends regarding communication workload for teams that use GPS. The first is that the command post is not relieved from work due to the GPS support. The second is that the ground chiefs operating on the simulated field are relieved from workload when their command post is supported by a GPS.

\section{Discussion}

The two participant groups, university students and crisis management professionals, differ in age, educational level and experiential background. The students are used to be evaluated and observed. Performing well during assessment is their means to show knowledge. The simulation system is far from important in their world of examinations. The professionals are not used to cameras, full-logging systems or researchers funded by the Swedish civil contingencies agency. Their way to demonstrate skills are based on good outcomes during response, not while being observed. Their management abilities are what they want to demonstrate. 


\subsection{Performance Students vs Professionals}

An observation when comparing the performance measure in results from study 1 and study 2 is that the students does perform better in terms of BurnedOutArea than the professionals independent on if they were using GPS or Paper Maps (Figure 4 and 5).

The performance situation here is slightly different for the two groups. Students have none or a very limited experience of crisis management, paper maps or GPS. The students appreciated the game, appreciated to beat the game and found satisfaction in their group performance.

The professionals have a solid experience base to use when managing these kinds of efforts, especially when the means are paper maps. Their experience, skills and methods for crisis management make them connect the game to command and control aspects as well as crisis management in general. Situations that occur during simulations are close enough to their rough everyday responsibilities during response. They use the time for team and individual training. They appreciate the game as a means to find winning concepts from a response perspective.

Three possible explanations for the students over all better performance are computer game, professional experience and team composition. 1) Computer game: The students have more experience from playing computer games than the professionals. A larger set of students did see the problem as a computer game task that they should solve. Win the game was often the goal. 2) Professional experience: The professionals did behave as professionals when solving the task. They knew that their behavior was observed and analyzed in a research project. They used the strategies that they were use to do in real life, like not using all the resources directly, discuss before acting, etc. They did see the simulated task's similarities to a real situation. They did not try to win the game as a game; they tried to do what they should have done in a real situation. They could relate the events in the simulation to their profession. Hence they practiced and reflected on strategies that they utilize in real life. 3) Team Composition: When the results were divided into the two team compositions interesting results appeared. Both the groups were professionals that work with crisis situations in their professions. Still they have different experiences and work tasks. Two main observations were that the mixed groups did not know each other as the rescue service teams did. A lot of task for the mixed group was to learn to work together as a team. Some of the mixed groups did see the day as a team training day. Another observation was that the command style did change depending on the profession.

An important observation is that if we compare the performance when using paper maps or GPS support it shows that both the students and the rescue service personnel performs better with GPS support.

\subsection{Communication Students vs Professionals}

Students communicate by far more via the text messages than professionals. The professionals are trained to communicate effectively, without adding to the confusion of the emergency situation, without taking precious time, and probably with a predisposition of consensus. The students were selected as volunteers and are likely 
the most extrovert partition of university students in general. The professionals were chosen because of their ability as crisis managers, being extrovert is far from a required feature in times of crises.

In relation to the GPS both students and professionals have the same results; the command post is not relieved from work due to the GPS support and it is the ground chiefs operating on the simulated field that are relieved from workload.

\subsection{The Complexity of Measuring Performance}

Measuring performance is complex. In study 1 and 2 the participants' task was to close out the forest fires. The basic performance measure should then be to count the burned out area as shown above. But the simulated world also contained houses etc, they too could be analyzed as a performance measure. The result of amount of BurnedOutHouses shows the same pattern. The students preformed better. It is not because the students considered the houses; they did not even mention them in their text messages. It is a consequence of their one goal, to extinguish fire effectively, out of a game point of view. The fire newer even reached the houses.

The professionals on the other hand, considered and mentioned the houses. They prioritized among them and agreed on rules for what to save and what to let burn. All on an experience based logic in order to practice what they need to know in real life. They fought for the houses they prioritized, and often, especially with the support of GPS, saved them, but not always and not as effective as the students, who did not even recognize the goal to save houses.

The question then is; what is performance, who performed best students or professionals?

\section{References}

1. Artman, H., Waern, Y.: Distributed cognition in an emergency Co-ordination Center. Cognition, Technology \& Work 1, 237-246 (1999)

2. Brehmer, B., Dörner, D.: Experiments With Computer-Simulated Microworlds: Escaping Both the Narrow Straits of the Laboratory and the Deep Blue Sea of the Field Study. Computers in Human Behaviour 9, 171-184 (1993)

3. Brehmer, B.: Microworlds and the circular relation between people and their environment. Theoretical Issues in Ergonomics Science 6(1), 73-93 (2005)

4. Dahlbäck, N., Karsvall, A.: Personality Bias in Volunteer Based User Studies? In: Proceedings of HCI 2000, vol. 2, pp. 49-50 (2000)

5. Dörner, D., Schaub, H.: Errors in Planning and Decision Making and the Nature of the Human Information Processing. Applied Psychology: An international review, Special Issue on Human Error, 433-453 (1994)

6. Granlund, H.: Experiential Learning in computer based simulation training - Experiences from research on team decision making. In: proceedings of 2008 International Conference on Information Technology in Education within CSSE, Wuhan, China (2008)

7. Granlund, R.: Web-based micro-world simulation for emergency management training. In: In Future Generation Computer systems, vol. 17, pp. 561-572. Elsevier, Amsterdam (2001); (best papers form the conference Websim 1999) 
8. Granlund, R.: Monitoring experiences from command and control research with the C3Fire microworld. Journal Cognition, Technology and Work 5(3), 183-190 (2004), ISSN 14355558

9. Granlund, R., Granlund, H., Johansson, B., Dahlbäck, N.: The Effect of a Geographical Information System on Communication in Professional Emergency Response Organizations. In: Proceedings of ISCRAM 2010, 7th International Conference on Information Systems for Crisis Response and Management (2010)

10. Granlund, R., Granlund, H.: Using Simulations to Study the Impact of GPS Information in Crisis Response Organizations. Submitted to ISCRAM 2011, 8th International Conference on Information Systems for Crisis Response and Management, Lisbon, Portugal, May 8-11 (2011)

11. Johansson, B., Trnka, J., Granlund, R.: the Effect of Geographical Information Systems on a Collaborative Command and Control Task. In: Van de Walle, B., Burghardt, P., Nieuwenhuis, K. (eds.) Proceedings of ISCRAM 2007, pp. 191-201. Delft, the Netherlands (2007)

12. Johansson, B., Trnka, J., Granlund, R., Götmar, A.: The Effect of a Geographical Information System on Performance and Communication of a Command and Control Organization. The International Journal of Human-Computer Interaction. Special issue on Naturalistic Decision Making with Computers. 26(2\&3), 228-246 (2010)

13. Lindgren, I., Smith, K.: Using microworlds to understand cultural influences on distributed collaborative decision making in C2 settings. In: Proceedings of the 11th The International Command and Control Research and Technology Symposium (ICCRTS), Cambridge, UK (2006); (Awarded the Willard S. Vaughan, Jr. Best Student Paper Award)

14. Lindgren, I., Smith, K.: National patterns of teamwork during an emergency management simulation. In: Proc. 50th Annual Meeting of the Human Factors and Ergonomics Society, San Francisco, CA (2006)

15. Smart, R.: Subject Selection Bias in Psychological Research. Canadian Psychologist 7a, 115-121 (1966) 